\section{Thonic bandage: A new appli- cation technique as a first step towards controlled compression? Reprocomp study}

\author{
Pierre Gonon \\ Thonic Innovation SAS, France
}

\section{Introduction}

Compression bandages are one of the corner stones of veno-lymphatic conditions management and all international publications agree on the fact that bandages have to be applied by trained practitioners. ${ }^{1}$

This is clearly understandable because the level of compression reached or, in other words, the dosage of the treatment, is the result of a complex equation (Laplace's Law) involving many factors: $P=$ $T x N x 4630 / C x W$ where $\mathrm{P}=$ sub-bandage pressure $(\mathrm{mmHg}), \mathrm{T}=$ bandage tension, $\mathrm{N}=$ number of layers, $\mathrm{C}=$ limb circumference $(\mathrm{cm})$ and $\mathrm{W}=$ bandage width $(\mathrm{cm}){ }^{1}$

It is important to notice that in this equation, 2 of the factors are operator dependant: the tension with which the bandage is applied and the number of layers (overlap). This is why international compression experts agree to say that the compression is not in the bandage but in the hands that apply it which is in total contradiction with the concept of controlled compression. These 2 factors will be the focus of this study.

A German study ${ }^{2}$ showed that, in practice, primary healthcare professionals struggled to reach the recommended sub-bandage pressures between 50 and $60 \mathrm{mmHg}$. The range of pressures reached went from 6 to $143 \mathrm{mmHg}$ and only $10 \%$ of them achieved the target.

Traditionally, the applicator creates the tension by stretching the bandage maintaining the roll at a distance from the limb. The resulting torque effect could explain part of these major discrepancies.

Thonic bandage's patented system allows to mechanically limit the stretchability of the elastic component to $30 \%$, which means it can be wound up under maximum tension before application. In this case, Thonic bandage can be applied by unwinding it in contact with the limb, which allows the application of a more regular and controlled tension.

\section{Objectives of the study}

The first objective of this study is to check whether stretching Thonic bandage before application allows reaching more reproducible pressures and to narrow the range of pressures achieved by an applicator. The second objective is to compare the sub-bandage pressures reached by different groups: people who have never applied a bandage before, patients, primary care professionals, and secondary care professionals.

\section{Materials and Methods}

The sub-bandage pressures achieved by 4 different bandaging systems (2 shortstretch +2 long stretch) will be measured in this study.

Both short stretch-bandaging systems will be applied traditionally and previously stretched at maximum strength. Both long stretch-bandaging systems will be applied as recommended.

Sub-bandage pressures will be measured with a Pico-Press system. In order to avoid any bias due to the 2 non operatordependant elements of Laplace's law, the measurements will be made on a plastic leg and the sensor will remain in exactly the same position for all measurements. For this reason, the compression levels reached by the different systems will not be of any clinical value. All bandages will also have the same width.

Each applicator will repeat 3 times and randomly the following applications: i) thonic bandage: applied traditionally; ii) thonic bandage: applied previously stretched; iii) short stretch bandage: applied traditionally; iv) short stretch bandage: applied previously stretched; v) long stretch bandage A: applied traditionally; vi) long stretch bandage B: applied traditionally.

Both long stretch bandages allow the delivery of compression force 1 (20 to 45 $\mathrm{cN} / \mathrm{cm})^{3}$ and force 2 (46 to $\left.100 \mathrm{cN} / \mathrm{cm}\right)^{3}$ with 2 different techniques: increase of stretch for one and increase of overlap for the other.

The average pressure reached in 3 applications and the range (maximum pressure - minimum pressure) will be calculated. Obviously, the lower the range, the most controlled the compression will be.

The participants will be split between 4 categories: i) group 1: people who have never applied a bandage before; ii) group 2: patients; iii) group 3: primary care professionals (nurses, physios, ...); iv) group 4: secondary care professionals (nurses, physios, ...).

[Veins and Lymphatics 2018; 7:7632]
Correspondence: Pierre Gonon, Thonic Innovation SAS, France.

E-mail: pierre.gonon@thonic.care

Conference presentation: International Compression Club (ICC) Meeting, Paris, 2017.

This work is licensed under a Creative Commons Attribution 4.0 License (by-nc 4.0).

CC Copyright P. Gonon, 2018

Licensee PAGEPress, Italy

Veins and Lymphatics 2018; 7:7632

doi:10.4081/vl.2018.7632

\section{Results and Conclusions}

\section{Initial results}

At this stage, 15 people who had never applied a bandage before have completed the study.

A more in-depth statistical analysis needs to be carried out but for this group of participants; it looks like we will probably reach the following conclusions: i) applying thonic bandage after having stretched it before helps reducing the average range substantially (12.2 mmHg vs $22.3 \mathrm{mmHg}$ ); ii) the same does not apply so much to the other short stretch system $(16.5 \mathrm{mmHg}$ vs $18.3 \mathrm{mmHg}$ ); iii) long stretch bandages generate lower ranges $(7.3 \mathrm{mmHg}$ and 9.5 $\mathrm{mmHg}$ vs $12.2 \mathrm{mmHg}$ and $16.5 \mathrm{mmHg}$ ); iv) increasing the compression level by increasing the overlap instead of the tension seems to create higher ranges $(9.5 \mathrm{mmHg}$ vs $7.3 \mathrm{mmHg}$ ).

\section{Next steps}

The study will be extended to the other 3 groups in the next few weeks. We should be able to present the results for at least 3 of the 4 groups at the ICC Meeting in Paris on December 9. Our intention is to follow-up on this study with a study on patients with real application conditions.

\section{References}

1. Lymphoedema Framework. Best practice for the management of lymphoedema. International Consensus. London: MEP Ltd.; 2006.

2. Protz K, Heyer K, Dörler $M$, et al. Kompressionstherapie - Kenntnisse und Anwendungspraxis. J Dtsch Dermatol Ges 2014;12:794-802.

3. IFTH measurements, norm NF G 30 104-1. 